\title{
Airway nitric oxide in asthmatic children and patients with cystic fibrosis
}

\author{
J. Dötsch*, S. Demirakça*, H.G. Terbrack**, G. Hüls**, W. Rascher*, P.G. Kühl*
}

Airway nitric oxide in asthmatic children and patients with cystic fibrosis. J. Dötsch, $S$. Demirakça, H.G. Terbrack, G. Hüls, W. Rascher, P.G. Kühl. (OERS Journals Ltd 1996. ABSTRACT: We evaluated the effects of asthma and cystic fibrosis on nitric oxide (NO) concentrations in the respiratory tract.

NO levels in orally exhaled air and nasal gas samples were studied in 90 asthmatic patients (4-14 yrs), 67 patients with cystic fibrosis (CF) (5-32 yrs), and 68 controls (4-34 yrs). NO concentrations measured by chemiluminescence were correlated with the patient's vital capacity, forced expiratory volume in one second (FEV1) and specific airway resistance.

In all groups, NO concentrations in orally-exhaled air correlated with the inhaled ambient NO $(r=0.85-0.91)$. At an ambient NO concentration of 0 parts per billion (ppb), asthmatic patients exhaled air with higher NO concentrations than cystic fibrosis patients and controls $(8.0 \pm 6.1 \mathrm{ppb}(\mathrm{n}=33)$; 4.9 $\pm 2.6 \mathrm{ppb}(\mathrm{n}=23)$; and 3.0 $2.5 \mathrm{ppb}(\mathrm{n}=37)$; respectively; $\mathbf{p}<\mathbf{0 . 0 0 1})$. Similar results were obtained for ventilation-adjusted orally-exhaled NO. Nasal NO concentrations were lower in patients with $C F(23 \pm 17 \mathrm{ppb})$ than in controls and asthmatics $(96 \pm 47$ and $103 \pm 64 \mathrm{ppb}$; $\mathbf{p}<\mathbf{0 . 0 0 1})$. There was no relationship between nasal or oral NO and pulmonary function tests.

Our results suggest that ambient NO levels influence NO concentrations in orallyexhaled air. Like adults, asthmatic children exhale more NO than their controls. Reduced nasal NO concentrations in patients with cystic fibrosis may reflect chronic epithelial cell damage or an increased mucosal barrier impeding NO diffusion into the airway.

Eur Respir J., 1996, 9, 2537-2540.
*Dept of Pediatrics and Neonatology and **Division of Pediatric Pulmonology, JustusLiebig University of Giessen, Germany

Correspondence: J. Dötsch

Dept of Pediatrics

Feulgenstr. 12

D-35385 Giessen

Germany

Keywords: Asthma

cystic fibrosis

nitric oxide

Received: March 41996

Accepted after revision August 221996

This study was supported by a grant from the Deutsche Forschungsgemeinschaft $(\mathrm{Ra}$ $326 / 3-2)$
Nitric oxide (NO) is a potent smooth muscle relaxant [1]. Isoenzymes of constitutive nitric oxide synthase (NOS) are present in human airway epithelial cells [2]. The induction of NOS has been demonstrated in asthmatic adults [3]. In vivo, this is reflected by increased NO concentrations in orally-exhaled air of adults with asthma [4]. Steroid therapy for asthma reduces the elevated NO levels in exhaled air to control values [5].

Little is known about the airway concentration of NO in children with chronic lung disease. Absence of NO production in four children with Kartagener's syndrome [6] has recently been reported.

To study airway NO concentrations in paediatric patients, we addressed the following questions: 1) Do asthma in childhood and cystic fibrosis (CF) affect NO levels in the airways? and 2) Is NO synthesis related to the severity of respiratory disease evaluated by pulmonary function tests?

Since NO concentrations from the nasopharynx are known to be very high compared to tracheal values [7, $8]$, nasal and orally-exhaled NO was analysed separately.

\section{Patients and methods}

The study was approved by the Ethics committee of the University of Giessen, and informed consent was obtained from patients and parents. Patients attending the out-patient clinic were included in this study. Patient characteristics are shown in table 1. CF was diagnosed by typical clinical presentation, sweat sodium analysis, nasal potential difference and determination of

Table 1. - Characteristics of patients with cystic fibrosis (CF), patients with asthma and healthy volunteers

\begin{tabular}{lccc}
\hline & CF & Asthma & Controls \\
\hline Patients n & 67 & 90 & 68 \\
Age yrs & $17(5-32)$ & $10(4-14)$ & $12(4-34)$ \\
Sex M/F & $29 / 38$ & $53 / 37$ & $38 / 30$ \\
Severity of disease n & & & \\
mild/moderate/severe & - & $26 / 60 / 4$ & \\
VC >80\% pred & 21 & - & \\
$50-80 \%$ pred & 27 & - & \\
$\quad<50 \%$ pred & 19 & - & \\
FEV1 >80\% pred & 24 & 73 & \\
$\quad 50-80 \%$ pred & 23 & 15 & \\
$\quad<50 \%$ pred & 20 & 2 & \\
sRaw <120\% pred & 25 & 45 & \\
sRaw 120-200\% pred & 24 & 37 & \\
sRaw >200\% pred & 18 & 8 & \\
Atopy & ND & 60 & ND \\
\hline
\end{tabular}

\#: median, and range in parenthesis; \% pred: percentage predicted; n: numbers of patients; M: male; F: female; VC: vital capacity; FEV1: forced expiratory volume in one second; $s R$ aw: specific airway resistance; ND: not determined. 
the genomic defect. Asthma was diagnosed according to established criteria [9], and graded according to the classification of the "International consensus report on diagnosis and treatment of asthma" [10]. Asthmatics and $\mathrm{CF}$ patients receiving topical or systemic steroids were excluded from the study. Patients with upper respiratory tract infections and smokers were excluded from the study, since these factors are known to influence airway NO concentrations [4, 11]. Healthy volunteers had normal clinical examination and no history of respiratory disease.

NO was measured with a chemiluminescence analyser (CLD 700; Eco Physics, Dürnten, Switzerland) sampling with a constant flow of $700 \mathrm{~mL} \cdot \mathrm{min}^{-1}$. The response time of the CLD 700 instrument to obtain $90 \%$ of the true value when the concentration of NO is suddenly changed is $25 \mathrm{~s}$. The system was calibrated using a mixture of $50 \pm 1$ parts per billion (ppb) NO in nitrogen, and pure nitrogen certified to contain $0 \pm 1$ ppb NO (Messer Griesheim, Siegen, Germany), allowing the verification of $0 \mathrm{ppb}$ NO in ambient air. Prior to patient measurements, the ambient NO concentration was recorded.

In the first step, ambient air was inhaled through the mouth with closed nasal airways (by nasal clamp), and gas was exhaled through Teflon tubing from which samples were aspirated and analysed immediately. Measurements of orally exhaled NO were made from the expired air of maximal breath manoeuvres. To allow the instrument to adjust to the patient's orally-exhaled NO concentration, 3-4 maximal expiratory manoeuvres (equivalent to approximately $30 \mathrm{~s}$ ) were carried out before the values were recorded. However, since one exhalation was not long enough for the instrument to react, NO was measured continuously during the five subsequent respiratory manoeuvres. Contamination with ambient air during the expiratory manoeuvre was prevented by using valves, preventing ambient air from entering the analysis limb of the tubing and allowing only expired air to access the analysis limb. In addition, a closed, flexible reservoir, which was confirmed not to absorb NO, prevented ambient air from penetrating into the analysis limb. Before each measurement, the reservoir was completely emptied. Between two expiratory movements, the reservoir supplied air from the last respiratory manoeuvre for analysis. Consequently, NO measurements from orally-exhaled air reflected a mixture of the entire exhalation volume. The mean NO concentration in the orally-exhaled air was calculated and recorded. To estimate lower airway NO production, mean NO values in the exhaled air were related to the patient's ventilation.

For direct nasal sampling, a nasal olive was placed in the vestibule of one nostril, avoiding contact with the nasal mucosa. The other nostril was closed and breathing continued through the mouth. When the NO concentration had reached a steady state, mean NO levels obtained from integration of nasal NO concentration over $60 \mathrm{~s}$ were recorded. The procedure was repeated for the other nostril. The mean NO concentration from both sides was calculated and used for further analysis.

In all patients and in 10 of the healthy volunteers, lung function tests were performed on the same occasion as NO measurements. Vital capacity (VC) and forced expiratory volume in one second (FEV1) were determined by spirometry, and specific airway resistance (sRaw) was calculated from body plethysmographic measurements [12].

Nonparametric data were analysed by Kruskal-Wallis and Mann-Whitney U-test. Bonferoni's correction was used for multiple comparisons [13]. The relationship between NO concentration and age was analysed by the least squares method according to Spearman. The relationship between ambient and orally-exhaled NO was analysed by linear regression. A p-value of less than 0.05 was considered significant. All results are given as mean \pm standard deviation.

\section{Results}

For all three study groups, orally-exhaled NO concentrations correlated significantly with the inhaled ambient concentrations of nitric oxide. Asthmatic patients: $r=0.85(n=90)$; CF patients: $r=0.91 \quad(n=67)$; controls: $r=0.91(n=68)(p<0.0001$ in all groups $)$. Figure 1 shows the relationship between ambient and orally-exhaled NO concentration. Because airway NO concentrations might be obscured by increased environmental NO concentrations measurements obtained at ambient NO $>0$ were excluded from further analysis. Mean FEV1 values for the groups of patients selected were: $78 \pm 39 \%$ of predicted (\% pred) (CF patients); $90 \pm 21 \%$ pred (asthmatics); and $99 \pm 14 \%$ pred (controls).

At an ambient NO concentration of $0 \mathrm{ppb}$, orallyexhaled air of asthmatics showed significantly higher NO concentrations than controls $(n=33$ and $n=37 ; p<$ $0.001)$ (fig. 2 and table 2). CF patients $(n=23)$ had slightly, but not statistically significant, higher orally-exhaled NO than the controls $(\mathrm{p}>0.05)$. Likewise, the minute ventilation related lower airway $\mathrm{NO}$ of the three groups was highest in asthmatics, followed by patients with CF and healthy volunteers $(93 \pm 82,73 \pm 55$, and $25 \pm 27 \mathrm{ppb}$ $\left.\times \mathrm{L} \cdot \mathrm{min}^{-1}\right)$. No relationship was observed between orally-exhaled air of patients with asthma or cystic fibrosis and pulmonary function tests $(r=0.06-0.15)$.

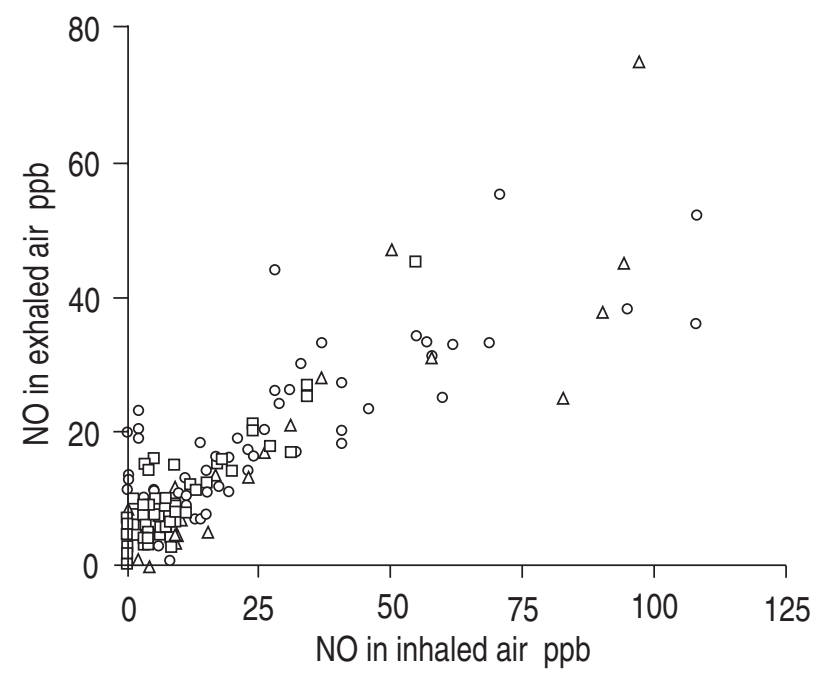

Fig. 1. - Relationship between ambient nitric oxide (NO) and orallyexhaled NO in 90 children with asthma (O), 67 patients with cystic fibrosis $(\square)$, and 68 healthy children and adolescents $(\Delta)$. ppb: parts per billion. 


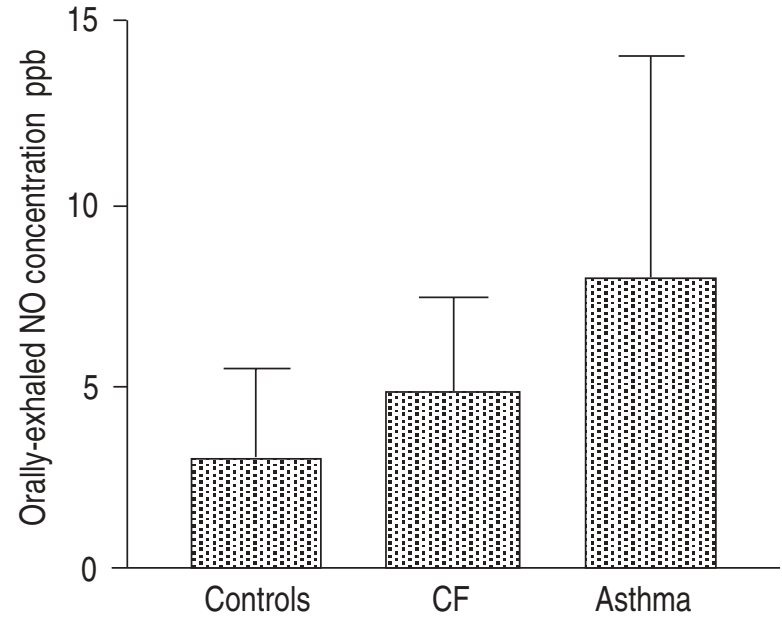

Fig. 2. - Nitric oxide (NO) concentrations at ambient NO of $0 \mathrm{ppb}$ in orally-exhaled air of patients with cystic fibrosis $(n=23)$, asthmatics $(n=33)$ and controls $(n=37)$. Values are presented as mean and SD. Results presented in figures 2 and 3 are from the same patients. CF: cystic fibrosis; ppb: parts per billion.

Table 2. - Nitric oxide (NO) concentrations in nasal and orally-exhaled air in the lower airways at ambient NO of $0 \mathrm{ppb}$ in patients with cystic fibrosis $(n=23)$, asthmatic patients $(n=33)$ and controls $(n=37)$

\begin{tabular}{|c|c|c|c|}
\hline & $\mathrm{CF}$ & Asthma & Controls \\
\hline Orally-exhaled NO ppb & $4.9 \pm 2.6$ & $8.0 \pm 6.1$ & $3.0 \pm 2.5$ \\
\hline $\begin{array}{l}\text { Orally-exhaled NO } \\
(<18 \text { yrs }) \text { ppb }\end{array}$ & $5.3 \pm 3.0$ & $8.0 \pm 6.1$ & $3.1 \pm 2.4$ \\
\hline Nasal NO ppb & $23 \pm 17$ & $103 \pm 64$ & $96 \pm 47$ \\
\hline Nasal NO $(<18$ yrs $)$ ppb & $27 \pm 22$ & $103 \pm 64$ & $101 \pm 49$ \\
\hline
\end{tabular}

values are presented as mean \pm SD. The NO concentrations are given for complete groups and for patients of less than $18 \mathrm{yrs}$ of age. ppb: parts per billion; CF: cystic fibrosis.

In comparison to controls and asthmatics, nasal NO concentrations were significantly reduced in $\mathrm{CF}$ patients (fig. 3 and table 2). There was no relationship between nasal NO concentrations and VC, FEV1 and $\mathrm{s} R \mathrm{aw}(\mathrm{r}=$ 0.05-0.12).

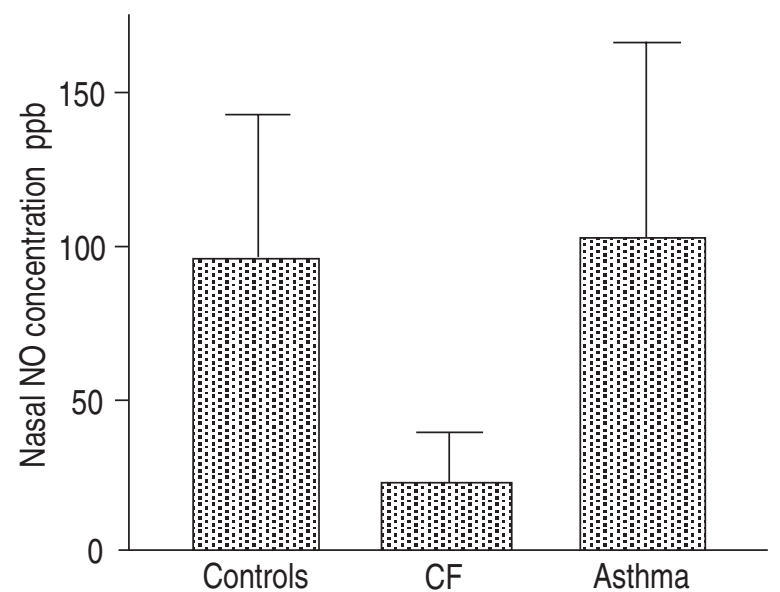

Fig. 3. - Nasal nitric oxide (NO) concentrations of patients with cystic fibrosis $(n=23)$, asthmatic patients $(n=33)$ and controls $(n=37)$ measured at ambient $\mathrm{NO}$ of $0 \mathrm{ppb}$. Values are presented as mean and SD. Results presented in figures 2 and 3 are from the same patients. CF: cystic fibrosis; ppb: parts per billion.

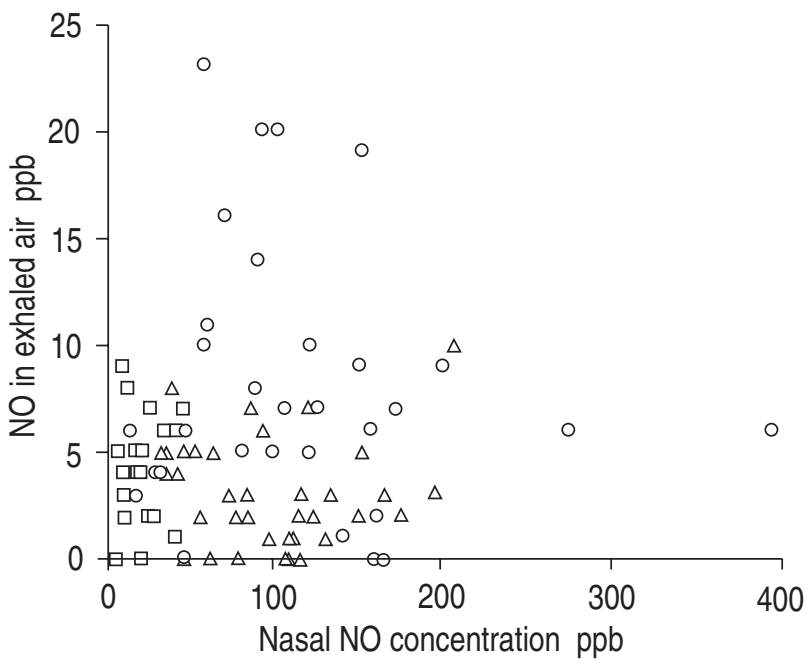

Fig. 4. - Relationship between nasal nitric oxide (NO) and orallyexhaled NO in 33 children with asthma (circles), 23 patients with cystic fibrosis (squares), and 37 healthy children and adolescents (triangles). Measurements were obtained at ambient NO of $0 \mathrm{ppb}$. There was no relationship between nasal and orally-exhaled NO in any group $(\mathrm{r}=0.03-0.17)$. ppb: parts per billion.

The patients' gender had no impact on nasal NO concentration in any of the groups. Nasal and orally-exhaled NO was not age dependent for any of the groups $(r=$ 0.06-0.30). CF patients and volunteers below 18 yrs had nasal and oral NO concentrations similar to the complete groups (table 2). There was no relationship between nasal and orally-exhaled NO in any group $(\mathrm{r}=0.03-0.17)$ (fig. 4).

\section{Discussion}

From a methodological point of view, one interesting observation from the present study is the impact of ambient NO on orally-exhaled NO concentrations. Although this is not surprising and might be suspected as a result of environmental contamination, to our knowledge only one study has related ambient NO concentrations of 0-7 ppb and orally-exhaled NO levels [14]. However, ambient NO concentrations in urban regions tend to be much higher on a number of days per year [15]. Consequently, to reduce environmental influences in our study, we only considered measurements at ambient NO levels of $0 \mathrm{ppb}$ for the comparison between patients with and without respiratory disease.

Orally-exhaled NO was slightly higher in patients with $\mathrm{CF}$ than in the controls, which can be explained by increased inflammatory activity in the lungs of these patients. On the other hand, the results demonstrate significantly reduced nasal NO concentrations in patients with $\mathrm{CF}$. We could find no association between the severity of ventilatory impairment and the patient's age. A destruction of epithelial cells and a loss of the ability to produce NO during the course of the disease might explain the reduced nasal NO values. Alternatively, the impaired clearance of mucus, leading to reduced diffusion of NO into the lumen of the nasal airways, seems possible. Both explanations would be consistent with the absence of nasal NO in four children with Kartagener's syndrome, which is characterized by immotile cilia [6]. In addition, this finding is supported by the observation 
of low NO concentration in exhaled air of smokers [4, 7], a condition characterized by chronic cellular damage and by an impaired mucociliary clearance due to the inhibitory effect of cigarette smoke on cilial function.

In adults with bronchial asthma, it has been reported that increased NO concentrations in orally-exhaled air returned to normal following the application of inhaled steroids $[4,5]$. Furthermore, an induction of NOS has been demonstrated in adults with asthma $[3,16]$. In the present study, NO concentrations in orally-exhaled air of asthmatic children were significantly higher than in controls. However, this difference might in fact be even more pronounced. Because of their limited ability to cooperate, in our paediatric population only NO in mixed expired air from larger airways and the alveolar space could be analysed, possibly masking a larger difference between asthmatics and their controls. In addition, NO is primarily produced in the upper airways [17]. Therefore, orally-exhaled NO might be a mixture of upper and lower airway NO if no closure of the soft palate can be achieved [18]. Since the complete closure of the soft palate requires a very high degree of compliance [18], this could not be performed in the young children in the present study. However, the mixture of nasal and oral NO appears to be less of a problem in this study population, since no relationship between oral and nasal NO concentrations could be demonstrated.

Another methodological difficulty for the measurement of NO in orally-exhaled air may be the slow response time of the CLD 700 instrument and the need for a high sampling volume, increasing the risk of contamination of the samples from ambient air. In this study, we prevented contamination by using valves and sealing the analysis limb from ambient air by means of a flexible reservoir. Finally, the vast majority of these patients had only mild or moderate asthma that might be associated with less increased NO levels. Therefore, studies of NO concentrations in exhaled air of children with severe asthma and of asthmatics with steroid treatment are warranted.

In conclusion, patients with cystic fibrosis showed substantially reduced nasal nitric oxide concentrations. Children with asthma had increased airway nitric oxide levels. For the evaluation of airway nitric oxide, ambient nitric oxide levels must be taken into account.

Acknowledgements: The authors thank H. Lindemann for his support in the conduct of this study and invaluable contributions to this manuscript. The technical assistance of J. Hellman, H. Hinkelthein, M. Johnson and $\mathrm{H}$. Keller was very much appreciated.

\section{References}

1. Moncada S, Higgs A. The L-arginine-nitric oxide pathway. N Engl J Med 1993; 329: 2002-2012.
2. Kobzik L, Bredt DS, Lovenstein CJ, et al. Nitric oxide synthase in human and rat lung: immunocytochemical and histochemical localization. Am J Respir Cell Mol Biol 1993; 9: 371-377.

3. Hamid Q, Springgall DR, Riveros-Moreno V, et al. Induction of nitric oxide synthase in asthma. Lancet 1993; 342: 1510-1513.

4. Persson MG, Zetterström O, Agrenius V, Ihre E, Gustafson LE. Single-breath nitric oxide measurements in asthmatic patients and smokers. Lancet 1994; 343: 146-147.

5. Kharitonov SA, Yates D, Robbins RA, Logan-Sinclair $\mathrm{R}$, Shinebourne EA, Barnes PJ. Increased nitric oxide in exhaled air of asthmatic patients. Lancet 1994; 343 : $133-135$.

6. Lundberg, JON, Weitzberg E, Norvall SL, Kuylenstierna $\mathrm{R}$, Lundberg JM, Alving K. Primarily nasal origin of exhaled nitric oxide and absence in Kartagener's syndrome. Eur Respir J 1994; 7: 1501-1504.

7. Gerlach H, Rossaint R, Pappert D, Knorr M, Falke KJ. Autoinhalation of nitric oxide after endogenous synthesis in nasopharynx. Lancet 1994; 343: 518-519.

8. Persson MG, Wiklund NP, Gustafsson LE. Endogenous nitric oxide in single exhalations and the change during exercise. Am Rev Respir Dis 1993; 148: 1210-1214.

9. $\quad$ McFadden ER, Ileen AG. Asthma. N Engl J Med 1992; 327: 1928-1937.

10. International consensus report on diagnosis and treatment of asthma. National Heart, Lung, and Blood Institute, National Institutes of Health. Bethesda, Maryland 20892. Publication No. 92-3091, March 1992. Eur Respir $J$ 1992; 5: 601-641.

11. Kharitonov SA, Yates D, Barnes PJ. Increased nitric oxide in exhaled air of normal human subjects with upper respiratory tract infections. Eur Respir J 1995; 8: 295-297.

12. Hilman BC, Allen JL. Clinical applications of pulmonary function testing in children and adolescents. In: Hilman $\mathrm{BC}$, ed. Pediatric Respiratory Disease: Diagnosis and Treatment. Philadelphia, London, Toronto, Montreal, Sidney, Tokyo, W.B. Saunders 1993; pp. 98-107.

13. O'Brian PC. Statistical considerations for performing multiple tests in a single experiment. 4. Performing multiple statistical tests on the same data. Mayo Clin Proc 1988; 63: 1043-1045.

14. Borland C, Cox Y, Higenbottam T. Measurement of exhaled nitric oxide in man. Thorax 1993; 48: 1160-1162

15. Schmidt M, Mampel U, Neumann U. Stickoxide. Gesundheitsschäden durch Luftverschmutzung. Heidelberg, Germany, Verlag Das Wunderhorn, 1987; 26-34.

16. Barnes PJ, Liew FY. Nitric oxide and asthmatic inflammation. Immunol Today 1995; 16: 128-130.

17. Schedin U, Frostell C, Persson MG, Jakobsson J, Andersson G, Gustafsson LE. Contribution from upper and lower airways to exhaled endogenous nitric oxide in humans. Acta Anaesth Scand 1995; 39: 327-332.

18. Kimberly B, Nejadnik B, Giraud GD, Holden WE. Nasal contribution to exhaled nitric oxide at rest and during breathholding in humans. Am J Respir Crit Care Med 1996; 153: 829-836. 